\title{
Article
}

\section{Reflecting on technology-enabled learning in neuroscience nurse education}

Jarvis, Anne

Available at http://clok.uclan.ac.uk/29635/

Jarvis, Anne ORCID: 0000-0002-8813-0250 (2019) Reflecting on technologyenabled learning in neuroscience nurse education. British Journal of Neuroscience Nursing, 15 (4). pp. 190-193. ISSN 2052-2800

It is advisable to refer to the publisher's version if you intend to cite from the work. 10.12968/bjnn.2019.15.4.190

For more information about UCLan's research in this area go to http://www.uclan.ac.uk/researchgroups/ and search for < name of research Group>.

For information about Research generally at UCLan please go to http://www.uclan.ac.uk/research/

All outputs in CLoK are protected by Intellectual Property Rights law, including Copyright law. Copyright, IPR and Moral Rights for the works on this site are retained by the individual authors and/or other copyright owners. Terms and conditions for use of this material are defined in the policies page.

\section{CLoK}

Central Lancashire online Knowledge www.clok.uclan.ac.uk

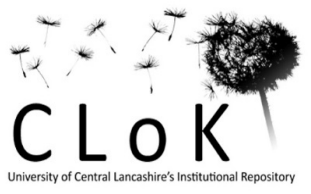


Author: Anne Jarvis, Senior Lecturer, Acute, Critical \& Emergency Team, School of Health Sciences, University of Central Lancashire, Preston.

\section{$\underline{\text { Reflecting on Technology Enabled Learning in Neuroscience Nurse Education }}$}

Digital technology is rapidly changing the lives of patients and NHS service providers. It is assisting in the storage and use of patient information and data, supporting faster diagnosis, streamlining hospital systems, and changing the way patient care is delivered (Donaldson, 2018). Digital capabilities are set to enhance education also, giving students a wider flexibility in relation to their learning (Morais, Mirando \& Alves, 2015), for example, digital story telling is widely accepted as having great merit in the education of nurses and other health professionals (Bennett, 2006). Within universities, academic staff and students have been encouraged to embrace these changes over recent years and the University of Central Lancashire (UCLan) has been part of this digital revolution piloting a software application from Microsoft named Teams. A model of reflection (what/so what/now what) (Driscoll \& Teh, 2001) will be used in this piece to explain the innovative digital method of delivery within neuroscience nurse education at UCLan.

\section{What}

The ongoing education of nurses is key to continuing professional development (CPD) and also a mandatory feature of revalidation for nurses (NMC, 2016). However, historically, there have been challenges to this process for nurses in relation to funding and within specialisms such as neuroscience, there have been additional difficulties. The release of a significant number of experienced nurses from one specialist unit to attend specialist 
educational courses impacts directly upon staff numbers and therefore directly upon the quality of service delivery and patient safety (Griffiths et al, 2018). Consequently, the relevant placement academic (link lecturer) collaborated with specialist clinical managers to question whether there could be a more flexible method of delivery of the CPD neuroscience module of learning. The digital revolution is changing the landscape of health care, meaning neuroscience nurses must be ready and prepared for the digital age in the health environment. Already we have seen changes in the form of electronic patient record keeping amongst other concepts as technology infiltrates the world of work. According to UK Government strategy (Department of Business, Energy \& Industrial Strategy, 2017), the next two decades will see ninety per cent of roles demanding some level of digital literacy and competency whilst almost a quarter of adults do not possess the most fundamental digital skills. Digital literacy is described as the ability to access and analyse digitally held resources in order that learning can take place (Radovanovic, Hogan \& Lalic, 2015). This literacy specifically in relation to educational application denotes digital competency (Spante, Hashemi, Lundin \& Algers, 2018). To ensure patient safety, both digital literacy and competency are vital for nurses and as part of nurse education, the profession must keep pace with technological development as it permeates into everyday clinical practice.

\section{So What}

As an academic, neuroscience nurse and specialist link lecturer, there was consideration of the challenge of technology enabled learning in the class room and the issues related to release of neuroscience nurses from the unit to attend CPD. There was a recognition that Teams may serve to bridge this gap in the blended delivery of a module of neuroscience nurse education. The university had piloted Teams amongst academic staff since 2017 and 
its capabilities were obvious. Teams allows a user-friendly platform through which a team of people can simultaneously edit documents, collaborate, view web-based resources, share information and enjoy chat which could be text or audio in nature between two individuals or a group. Mindful that authenticity was potentially key in this process and also that digital literacy may often be higher in the student cohort than that of the academic tutor (Radovanovic, Hogan \& Lalic, 2015), as an academic and a nurse, there was an obligation to lead by example. Therefore, immersion in the digital world was necessary in order to understand the software if the expectation was that the students should comprehend this; this change would be driven by an appreciation of the student perspective (Jarvis, 2010). In the evolving health environment, which is seeing the ongoing development of the nurse role plus the potential changes to nurse education coupled with the ongoing technological development, it was pertinent to take this innovative digital step with neuroscience nurse education. With a cohort of ten neuroscience nurses, the primary aim of the Teams platform was to allow students to engage with study on their own terms, whenever it may be suitable for them and this was how the platform was marketed to them. A virtual group was created that allowed interaction between the students and the tutor, the module resources were also loaded and embedded into the Teams site. The concept of Teams was introduced to the students on the first day of the module.

\section{"I'm a bit apprehensive about using Teams" \\ "found Teams daunting at first, the flexibility is good. I did find it easier and helpful as} time went on"

An initial poll with the students demonstrated (Figure 1) that the majority were excited to be using this new concept. 


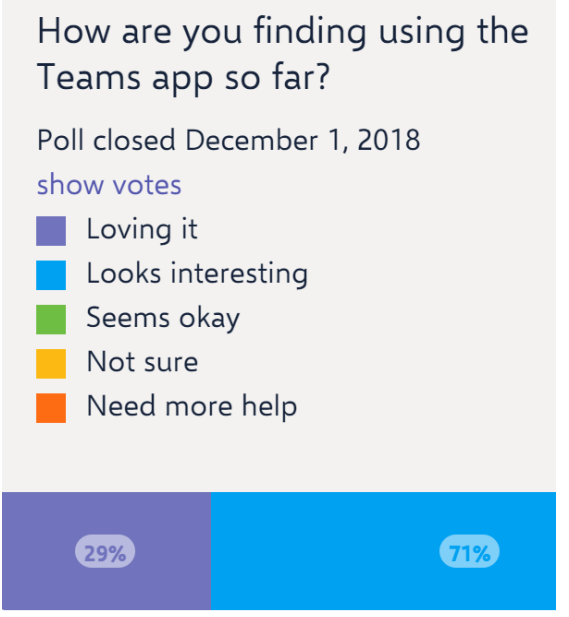

Figure 1. Poll demonstrating initial thoughts in relation to Teams

There was anticipation that this platform would create a professional forum for the students to engage with, a virtual class room within which they could learn, communicate and share concepts and knowledge. There was acknowledgement and mindfulness in relation to digital access and inclusivity which generated some apprehension. However, due to the portability of this platform, there needn't have been any concern; students were engaging with it during break times at work, even if this was during the night shift. Arguably, inclusivity was enhanced by this mode of delivery.

"The Teams application is brilliant to keep up to date with the group whilst at work"

"I like the availability of being able to work at home and communicate through Teams"

Teams was introduced primarily as a way of bringing a virtual learning environment to the students which was portable and flexible. Using the functions of the embedding of resources such as video, power point, websites and anatomy resources, the group engaged in several directed learning sessions at a time that suited them. 
"I liked the easy access of module content"

This was combined with regularly spaced face to face sessions at the university for approximately fifty per cent of the time. The cohort, encouraged by the tutor, adopted a collective approach focusing on peer support through the sharing of experiences, together with underpinning clinical and academic knowledge. Following each period of directed study, students would post what they had learned to the Teams site to demonstrate their engagement. Work that was posted proved not only to be interesting but on occasion, sparked further group debate and discussion.

\section{"I love the Teams space, it is the first time I have done something like this"}

The secondary aim of the application was to foster the idea of learning from each other. The cohort members were situated in both medical and surgical neuroscience placements and so were keen to learn from each other and embrace the platform into their learning. Students openly engaged with each other sharing articles that they had found during their individual literature searches for example.

"Teams is a very useful tool"

It was interesting to find that Teams acted as a mechanism of group and peer support as the module of learning progressed with some students coaching other peers. Teams also allowed group support to be administered by the tutor in relation to topic knowledge, assignment writing or module assessment. Students submitted formative assessment through the application seen by the whole group and the tutor could provide formative feedback which was also seen by the whole group thereby addressing the support of the wider group and continuing development in relation to the assessment. 
Digital literacy clearly varied within the group, which was no surprise as the digital divide is recognised as the difference between digital capability amongst individuals (Spante, Hasheemi, Lundin \& Algers, 2018). This created some difficulties initially because some students were more reluctant than others who had the confidence to engage with Teams. This was monitored by the tutor and encouraged, the private chat function utilised if necessary to communicate individually with a student privately. Moderation or encouragement of content input from students could also be carried out by the tutor if necessary. The tutor monitored the site each working day and posted weekly words of encouragement and also feedback to individual comments or questions. Professionalism was adopted and encouraged within the Teams site at all times in accordance with NMC professional values and standards and the code (NMC, 2014; NMC, 2015).

In module feedback, there was specific comment from students regarding the impact that the use of this platform had on their learning - many students commented positively about the application. Quotes from neuroscience nurses in module feedback are included throughout this piece. It seems that most students felt as if they were part of a cohesive group together with the tutor.

"Teams works well as a good source of communication with other students and the tutor" The idea of belonging is an important one when studying and appears to be somewhat intertwined with engagement level (Masika \& Jones, 2016). The fostering of these factors 
has recently been at the forefront of nursing and wider university education simply because of their associative link with success. This becomes increasingly important when nurses are completing some of the course of learning at a distance (Kahu, 2014).

\section{Now What}

On reflection, it would seem the most beneficial approach for the student to foster the expectation that digital capability will be part of their learning journey, also to emphasise to the student that their engagement is directly linked to success (Masika \& Jones, 2016). Even though pedagogy underpins the technology, the technology is certainly informing practice in the provision and facilitation of an engaging curriculum design (Biggs \& Tang, 2007).

The Teams software harnesses all the contemporary characteristics of social media platforms such as the tagging or liking of posts, it is user friendly and portable however, used in this manner, Teams professionalises this concept allowing space for collaboration in a professional online learning community (Bauer \& Kiger, 2017). In this way, the formulation of positive professional and collaborative working relationships in clinical practice was mirrored and professionalism in relation to this was developed.

\section{"I Love Teams, I've really enjoyed submitting work there and peer reviewing; I think this is a great way to develop learning"}

Students still felt that the workload was significant, and it is vital to acknowledge as the Royal College of Nursing (RCN) have in their recent report, that nurses maintaining their continuing professional development (CPD) need time as well as funding opportunities to access studies and to experience success in their studies (RCN, 2018). According to the RCN report, the access to CPD opportunities for nursing staff is vital to the professional 
revalidation process and also to ensure patient safety. There will be further negotiation with neuroscience nurse managers in relation to flexible methods of release to raise the amount of time spent on this CPD module.

On balance, there appears to be overwhelming evidence that this approach has been a positive one within neuroscience nurse education with neuroscience nurses leading the way in this innovative area of nurse education. The plan is now to introduce the Teams software to other modules of learning within the nursing and wider health care programmes.

To conclude, in this example, Teams has been shown to provide nurses with a method of flexible access to CPD education. It could be argued that this method is facilitating the preparation of neuroscience nurses for the digital work place. The future of health care in neurosciences and other areas will continue to see developments throughout the digital age, Roberts \& Williams (2017) suggest that mobile applications accessed via smart devices at the patient bedside will be a further digital development in a bid to continue to close the gap between theory and practice in nurse education. Digital technology may be used to build platforms to unite staff, other key professionals and individuals involved in supporting the learning journey. This method brings digital technology into the education of neuroscience nurses and catapults them to the forefront of digital education. It will, no doubt, support nurses to keep pace of changes in technology in relation to the health and educational arena and shape expectations within the workplace preparing them to be 'digiready'.

(2103 words) 


\section{References:}

Bauer, R. \& Kiger, S. (2017) Nursing living-learning communities and student retention: A qualitative study. Nursing Education Perspective. Vol. 38(2), 75-79.

Bennet, B. (2006) Gaining Understanding from Patients' Stories to Inform Neuroscience Nursing Practice British Journal of Neuroscience Nursing Vol.3(7), 308-312.

Biggs, J. \& Tang, C. (2007) Teaching for Quality Learning at University. (3 ${ }^{\text {rd }}$ edition). Maidenhead: Open University Press.

Department of Business, Energy \& Industrial Strategy (2017) Industrial Strategy: building a Britain fit for the future. London, UK: Department of Business, Energy \& Strategy.

Donaldson, I. (2018) Delivering the digital future. British Journal of Nursing. 27(19), 1136.

Driscoll, J. \& Teh, B. (2001) The potential of reflective practice to develop individual orthopaedic nurse practitioners and their practice. Journal of Orthopaedic Nursing. 5, 95-103.

Griffiths, P. Maruotti, A. Saucedo, A.R. Redfern, O.C. Ball, J.E. Briggs, J. Dall'ora, C. Schmidt, S. Smith, G.B. (2018) Nurse staffing, nursing assistants and hospital mortality; a retrospective longitudinal study. British Medical Journal Qual Saf. 0:1-9. Retrieved from doi:10.1136/bmjqs-2018-008043

Jarvis, P. (2010) Adult education and life long learning. (4 ${ }^{\text {th }}$ Edition). Oxford: Routledge Falmer. 
Kahu, E. (2014) Increasing the emotional engagement of first year mature aged distance students: Interest and belonging. The International Journal of the First Year of Higher Education. Vol. 5(2), 45-55.

Masika, R. \& Jones, J. (2016) Building student's belonging and engagement: Insights into higher education students experience of participating and learning together. Teaching in Higher Education. Vol 21(2),

Morais, C. Miranda, L. \& Alves, P. (2015) The use of digital and educational resources in the support to learning in higher education. EAI Endorsed Transactions on E-Learning. Vol 2(5), 1-10.

Nursing \& Midwifery Council (2018a). Future Nurse: Standards of Proficiency for Registered Nurses. London, United Kingdom: NMC.

Nursing \& Midwifery Council (2018b). The Code: Professional Standards of Practice \& Behaviour for Nurses, Midwives \& Nursing Associates. London, United Kingdom: NMC.

Nursing \& Midwifery Council (2016) Revalidation: your step by step guide through the process. London, United Kingdom: NMC

Radovanovic, D. Hogan, B. \& Lalic, D. (2015) Overcoming digital divides in higher education: Digital literacy beyond Facebook. New Media \& Society. Vol 17(10), 1733-1749. Roberts, D. \& Williams, A. (2017) The Potential of Mobile Technology (\#MoTech) to Close the Theory Practice Gap. Nurse Education Today. Vol 53: 26-28. 
Royal College of Nursing (2018) Investing in a safe and effective workforce: Continuing professional development for nurses in the UK. London, UK: RCN

Spante, M. Hashemi, S.S. Lundi, M. \& Algers, A. (2018) Digital competence and digital literacy in higher education research: Systematic review of concept use. Cogent Education. Vol 5: 1-21. 